02

\title{
Оптические и электрохромные свойства тонких пленок амбиполяных полиимидов с пендантными группами на основе производных тоиксантенона
}

\author{
() В.Н. Кручинин ${ }^{1}$, Д.С. Одинцов ${ }^{2}$, Л.А. Шундрин ${ }^{2}$, И.К. Шундрина ${ }^{2}$, С.В. Рыхлицкий ${ }^{1}$, \\ Е.В. Спесивцев ${ }^{19}$, В.А. Гриценко ${ }^{1,3,4}$
}

${ }^{1}$ Институт физики полупроводников им. А.В. Ржанова СО РАН, 630090 Новосибирск, Россия

${ }^{2}$ Институт органической химии им. Н.Н. Ворожцова СО РАН, 630090 Новосибирск, Россия

${ }^{3}$ Новосибирский государственный университет, 630090 Новосибирск, Россия

${ }^{4}$ Новосибирский государственный технический университет, 630073 Новосибирск, Россия

๑e-mail: evs@isp.nsc.ru

Поступила в редакцию 23.06.2021 г.

В окончательной редакции 03.08.2021 г.

Принята к публикации 05.08.2021 г.

\begin{abstract}
Методами спектральной эллипсометрии, спектрофотометрии и спектроэлектрохимии исследованы оптические и электрохромные свойства тонких пленок, полученных методом центрифугирования из растворов, содержащих амбиполярные полиимиды с пендантными группами на основе $9 H$-тиоксантен-9-она и его $S$-диоксидного производного. Показано, что спектральные зависимости показателя преломления и коэффициента поглощения, а также электрохромные свойства тонких пленок полиимидов в условиях электрохимического восстановления и окисления сильно зависят от типа пендантной группы. На основании оценок ширины запрещенной зоны сделан вывод о возможном перспективном использовании тонких пленок полиимидов в качестве рабочих слоев в мемристорах нового типа.
\end{abstract}

Ключевые слова: мемристоры, диэлектрические пленки, амбиполярные полиимиды, эллипсометрия, электрохромизм.

DOI: $10.21883 / \mathrm{OS} .2021 .11 .51638 .2473-21$

\section{Введение}

Одним из наиболее перспективных компонентов для создания энергонезависимой памяти нового поколения является мемристор, работа которого основана на обратимом переходе диэлектрической пленки из высокоомного состояния в низкоомное при протекании импульса тока. В настоящее время общепринято представление о том, что переход в низкоомное состояние происходит за счет образования филамента (тонкой проводящей нанопроволоки диаметром $1-5 \mathrm{~nm})$, малый размер которого открывает возможности разработки резистивной матрицы памяти терабитного масштаба [1].

Важнейшим параметром мемристора является величина окна памяти - разность между сопротивлением мемристора в высокоомном и низкоомном состояниях. В низкоомном состоянии сопротивление задается проводящим филаментом, тогда как в высокоомном состоянии - проводимостью диэлектрической пленки. Проводимость диэлектрической пленки зависит от величин потенциальных барьеров для электронов и дырок на границе металл/диэлектрик. Величины потенциальных барьеров для электронов и дырок, в свою очередь, за- висят от ширины запрещенной зоны $E_{g}$. Чем больше $E_{g}$, тем больше барьеры для инжекции электронов и дырок и тем меньше проводимость диэлектрика и больше окно памяти мемристора [2].

В случае, если проводимость диэлектрика определяется локализованными электронными состояниями (ловушками), в качестве механизма проводимости может выступать ионизация кулоновских ловушек в электрическом поле (эффект Френкеля [3]), при этом вероятность ионизации ловушки в эффекте Френкеля экспонендиэлектрикациально зависит от оптической диэлектрической проницаемости $\varepsilon_{\infty}=n^{2}$, где $n-$ показатель преломления [4].

Мемристорный эффект наблюдается в широком классе различных неорганических материалов: перовскитных пленках типа $\mathrm{SrTiO}_{3}$, диэлектрических оксидах $\mathrm{TiO}_{2}$, $\mathrm{HfO}_{2}, \mathrm{ZrO}_{2}, \mathrm{Ta}_{2} \mathrm{O} 5, \mathrm{SiO}_{x}, \mathrm{GeO}_{x}$, нитридах $\mathrm{SiN}_{x}, \mathrm{SiO}_{x} \mathrm{~N}_{y}$, а также в некоторых классах органических пленок.

Разработка мемристоров на основе органических полимеров, в частности полиимидов (ПИ), также рассматривается как перспективное направление благодаря ключевым свойствам ПИ: относительно легкой вариабельности их электрических свойств, в частности $E_{g}$, 


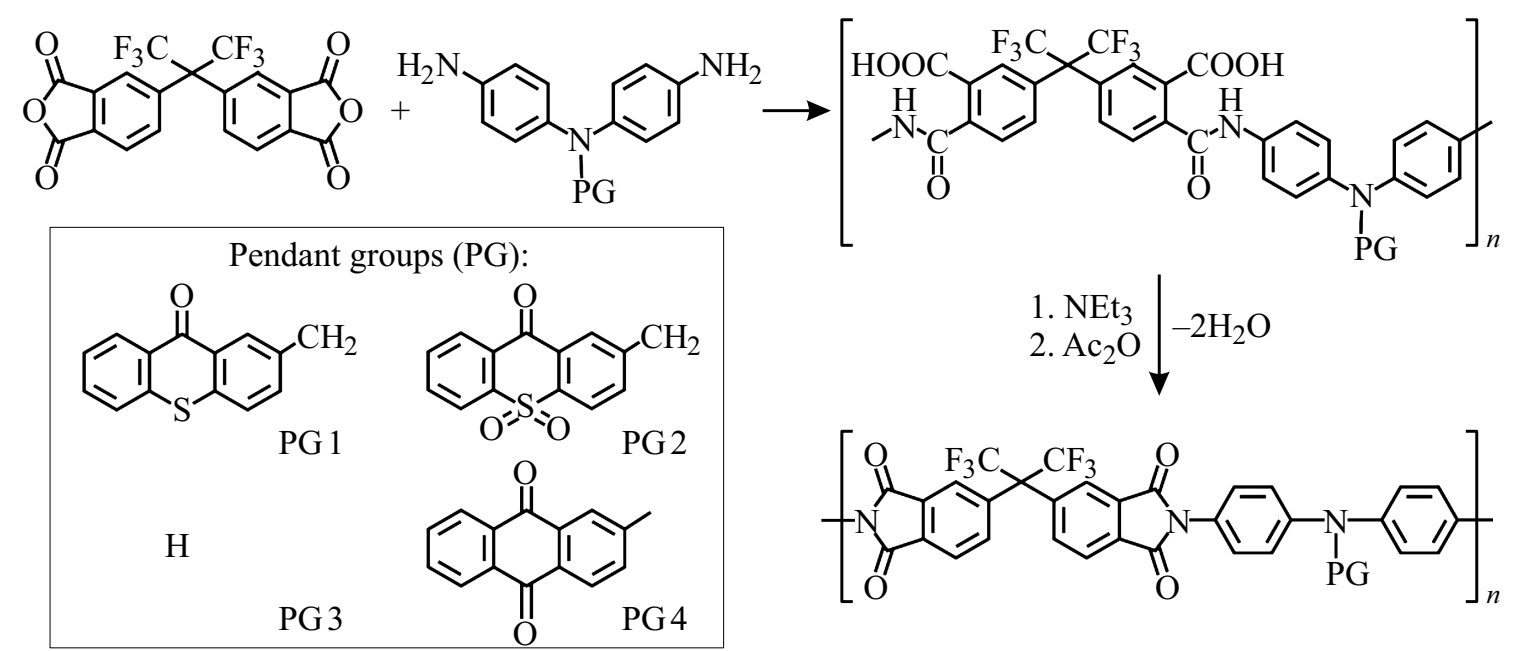

Рис. 1. Схема синтеза и структуры полиимидов (ПИ 1-4) с пендантными группами тиоксантенового ряда и антрахинона.

путем изменения структуры основной цепи полимера и/или введения пендантных (боковых) групп различной природы [5,6], высокой механической устойчивости ПИ и хорошей гибкости полиимидных пленок, их совместимости с полупроводниковыми платформами [7,8], высокой термостабильности [9] и относительно легким производством трехмерных массивов на их основе $[5,10,11]$.

Целью работы является изучение дисперсии показателя преломления и коэффициента поглощения, оценка ширины запрещенной зоны и исследование электрохромных свойств тонких пленок, содержащих амбиполярные полиимиды с новыми пендантными группами на основе 9H-тиоксантен-9-она и его S-диоксидного производного для возможного применения их в качестве рабочих слоев в мемристорах нового типа. Для сравнения изучены также свойства полиимида, не содержащего пендантной группы и описанного в литературе полиимида с антрахиноновой пендантной группой [12].

\section{Экспериментальная часть}

\section{Синтез полиимидов}

ПИ с пендантными группами, структуры которых показаны на рис. 1, были синтезированы двухстадийным методом, включающим синтез соответствующих полиамидных кислот с последующей химической имидизацией [13]. Выходы ПИ, их вязкости, молекулярно-массовые характеристики, термостойкость и электрохимические свойства описаны в работе [13].

\section{Получение пленок полимеров ПИ 1-4 на кремниевых пластинах}

Пленки полимеров ПИ 1-4 наносились на кремниевые пластины $\mathrm{Si}(100)$ КДБ диаметром $40 \mathrm{~mm}$ методом центрифугирования в насыщенных парах растворителя.
Для центрифугирования использовалась модифицированная центрифуга MiniSpin, оборудованная роторной насадкой собственной конструкции, представляющей собой хорошо центрированную относительно оси вращения ротора центрифуги круглую герметичную камеру с плоским основанием и толщиной $3 \mathrm{~mm}$. В центральную часть камеры помещалась и закреплялась кремниевая пластина, предварительно обработанная $10 \%$ раствором HF для удаления оксидной пленки. На планарную сторону пластины по ее центру наносилось $50 \mu 1$ 1\% раствора ПИ 1-4 в перфторацетоне. Дополнительно для создания насыщенной атмосферы паров растворителя $100 \mu 1$ чистого растворителя помещалось в виде капель по периферии пластины в пространство между краем пластины и стенкой камеры. Камера герметично закрывалась плоской полипропиленовой крышкой и выдерживалась $2 \mathrm{~min}$, что, в силу летучести перфторацетона, было достаточно для создания атмосферы, насыщенной парами растворителя. Центрифугирование проводилось при $800 \mathrm{rpm}$ в течение $60 \mathrm{~s}$. Далее образец выдерживался в закрытом состоянии в течение $2 \mathrm{~min}$, после чего камера открывалась, а пластина с нанесенным слоем полимера сушилась $30 \mathrm{~min}$ на воздухе при комнатной температуре, а затем при $120^{\circ} \mathrm{C}$ в сушильном шкафу. Образец кремниевой пластины с нанесенной пленкой в сравнении с чистой пластиной кремния показан на рис. 2.

\section{Спектральная эллипсометрия}

Оптические свойства органических пленок, нанесенных на кремниевые пластины, исследованы с помощью спектрального эллипсометра „Эллипс-1881САГ“ (ИФП CO РАН) в диапазоне энергий кванта световых волн $E=1.13-4.96 \mathrm{eV}$ с шагом $0.01 \mathrm{eV}$ [14]. Измерение спектральных зависимостей эллипсометрических углов $\Psi(E), \Delta(E)$ проводилось в центре кремниевой пластины 


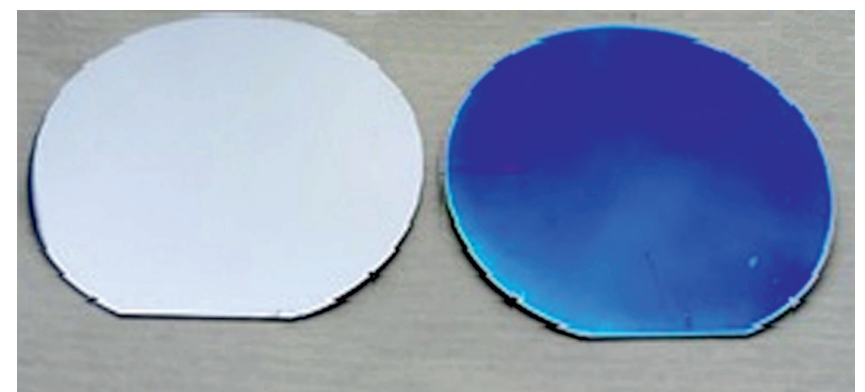

Рис. 2. Чистая кремниевая пластина (слева) и пластина с нанесенной тонкой пленкой ПИ 4 (справа).

по четырехзонной методике с усреднением по всем зонам, при этом диаметр светового пучка на поверхности исследуемого образца не превышал $3 \mathrm{~mm}$. Спектры $\Psi(E), \Delta(E)$ измерялись при трех значениях угла падения луча света на образец $-50^{\circ}, 60^{\circ}, 70^{\circ}$. Решение обратной задачи эллипсометрии и расчет спектральных зависимостей показателя преломления $n\left(E_{i}\right)$, коэффициента поглощения $\alpha\left(E_{i}\right)$ осуществлялись в соответствии с простой однослойной моделью отражающей системы: среда-пленка-подложка для каждой точки спектра $E_{i}$ независимо при использовании трех пар значений $\Psi\left(E_{i}\right)$, $\Delta E_{i}$ для $\phi_{0}=50^{\circ}, 60^{\circ}, 70^{\circ}$ [15]. Толщина пленок при этом определялась предварительно в области прозрачности пленок $(\alpha=0, E=1.96 \mathrm{eV})$. Методика эллипсометрических измерений и расчетов подробно описана в работе [16].

\section{Исследование электрохромных свойств}

Электрохромизм ПИ 1-4 измерялся в условиях электрохимического восстановления и окисления пленок полиимидов, нанесенных растворным методом на ITOэлектрод, служивший в качестве рабочего. Для измерения электрохромных свойств использовалась электрохимическая ячейка, сконструированная на основе стандартной кварцевой кюветы для оптических измерений с длиной оптического пути $1 \mathrm{~cm}$ - аналогично ячейке, описанной в работе [12]. В качестве электрода сравнения и вспомогательного электрода служили серебряная проволока и платиновая проволока петлеобразной формы соответственно. Ячейка помещалась в кюветное отделение UV-VIS-NIR-спектрофотометра „HР 8453“ с диодной матрицей, синхронизированного с потенциостатом „Elins“ (Россия). Измерения проводились в режиме ступенчатой развертки потенциала с шагом $150 \mathrm{mV}$ в диапазоне отрицательных потенциалов $(0>E>1.85 \mathrm{~V}$ - восстановительный электрохромизм) и отдельными экспериментами в диапазоне положительных потенциалов $(0<E<2.1 \mathrm{~V}$ - окислительный электрохромизм). В спектроэлектрохимических экспериментах оптические спектры измерялись в „дифференциальном режиме“: $D-D_{\text {blank }}(\lambda)$, где $D-$
Таблица 1. Оптические свойства пленок ПИ 1-4, нанесенных центрифугированием на кремниевые пластины

\begin{tabular}{c|c|c|c|c|c}
\hline \multirow{2}{*}{ Образец } & \multirow{2}{*}{$d, \mathrm{~nm}^{*}$} & $n(1.96 \mathrm{eV})$ & \multicolumn{2}{|c|}{ Пики поглощения, $\mathrm{eV}$} & \multirow{2}{*}{$E_{g}, \mathrm{eV}$} \\
\cline { 4 - 5 } & & & 1 & 2 & \\
\hline ПИ 1 & 39.2 & 1.642 & - & 4.29 & 3.42 \\
ПИ 2 & 44.9 & 1.663 & - & 4.31 & 3.15 \\
ПИ 3 & 41.5 & 1.691 & - & 4.22 & 2.49 \\
ПИ 4 & 28.5 & 1.666 & 2.66 & 4.39 & 2.23
\end{tabular}

Примечание. * — толщина измерялась в центре пластины.

Таблица 2. Характеристические полосы поглощения нейтральных пленок ПИ 1-4 и в условиях их электрохимического восстановления и окисления на ITO-электроде

\begin{tabular}{c|c|c|c}
\hline $\begin{array}{c}\text { Полиимидная } \\
\text { пленка }\end{array}$ & $\begin{array}{c}\lambda_{1}, \mathrm{~nm} \\
(E, \mathrm{eV})^{\mathrm{a}}\end{array}$ & $\begin{array}{c}\lambda_{2}, \mathrm{~nm} \\
(E, \mathrm{eV})\end{array}$ & $\begin{array}{c}\lambda_{3}, \mathrm{~nm} \\
(E, \mathrm{eV})\end{array}$ \\
\hline \multicolumn{4}{c}{ Нейтральное состояние } \\
\hline ПИ 1 & $297(4.17)$ & $323(3.84)$ & - \\
ПИ 2 & $294(4.22)$ & $336(3.69)$ & - \\
ПИ 3 & $297(4.17)$ & $320(3.87)$ & - \\
ПИ 4 & $309(4.01)$ & $353(3.51)$ & $460(2.70)$ \\
\hline \multicolumn{4}{c}{ Электрохимическое восстановление } \\
\hline ПИ 1 & $363(3.42)$ & $409(3.03)$ & $683(1.82)$ \\
ПИ 2 & $355(3.49)$ & $467^{\mathrm{b}}(2.65)$ & - \\
ПИ 3 & $354(3.50)$ & $386(3.21)$ & $566(2.19)$ \\
ПИ 4 & $344(3.60)$ & Эо) & \\
\hline \multicolumn{4}{c}{ Электрохимическое окисление } \\
\hline ПИ 1 & $378(3.28)$ & $446(2.78)$ & $754(1.64)$ \\
ПИ 2 & $378(3.28)$ & $488(2.54)$ & $772(1.61)$ \\
ПИ 3 & $376(3.30)$ & $443(2.80), 478(2.59)$ & $766(1.62)$ \\
ПИ 4 & $395(3.14)$ & $463(2.68)$ & $780(1.59)$
\end{tabular}

Примечание. а - в скобках дана соответствующая энергия кванта, $\mathrm{b}$ - полосы поглощения низкой интенсивности.

плотность поглощения, $\lambda-$ длина волны, $D_{\text {blank }}(\lambda)-$ спектры нейтральных пленок ПИ 1-4, взятых в качестве бланка $(D(\lambda)=0$ для всего диапазона измеряемых длин волн до начала сканирования потенциала). Отметим, что в режиме „дифференциального“ измерения электрохромного поведения пленок наблюдается положительное поглощение, если внутри полимерного слоя при определенном потенциале образуются новые оптически активные частицы, а „отрицательное“ поглощение соответствует уменьшению концентрации нейтральных фрагментов полимеров в исходных пленках до начала сканирования потенциала. Электрохромные измерения проводились в ацетонитриле, в котором ПИ 1-4 не растворимы, а пленки хорошо удерживаются на рабочем ITО-электроде. В качестве фонового электролита служил $0.1 \mathrm{M}$ раствор $\mathrm{Et}_{4} \mathrm{NClO}_{4}$. 

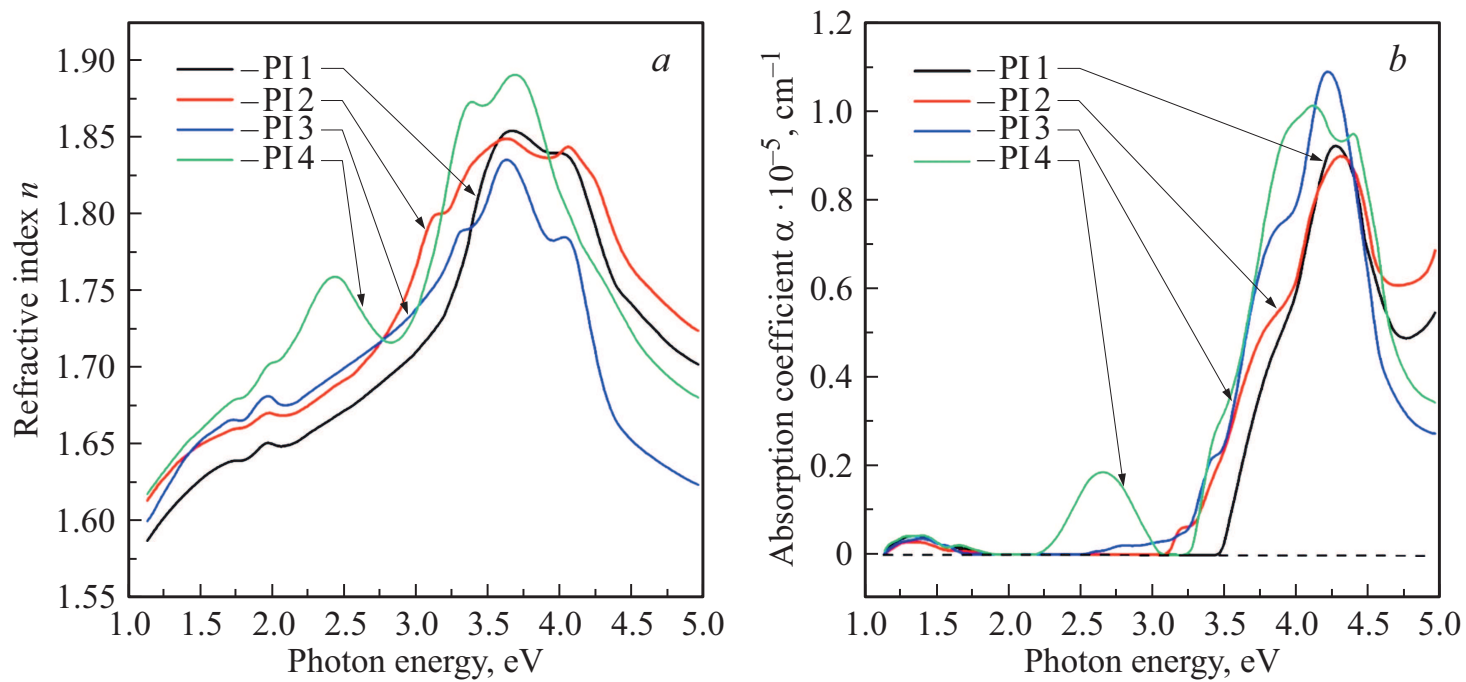

Рис. 3. Спектральные зависимости пленок ПИ (PI) 1-4: $a-$ показателя преломления, $b-$ коэффициента поглощения.
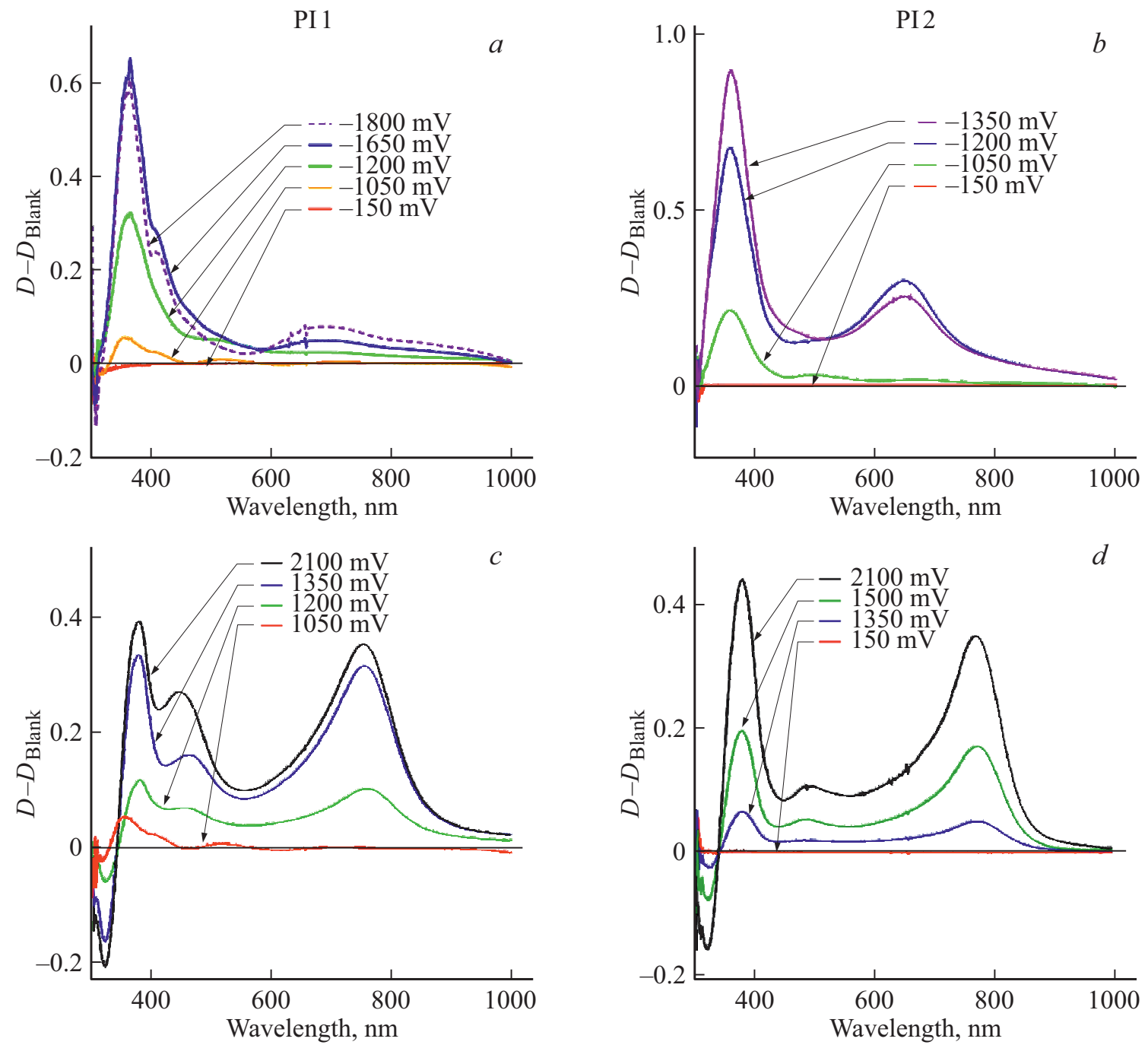

Рис. 4. Электрохромизм полиимидных пленок ПИ 1 (PI 1$)$, ПИ 2 (PI 2$)$ в восстановительной $(a, b)$ и окислительной $(c, d)$ областях потенциалов. 

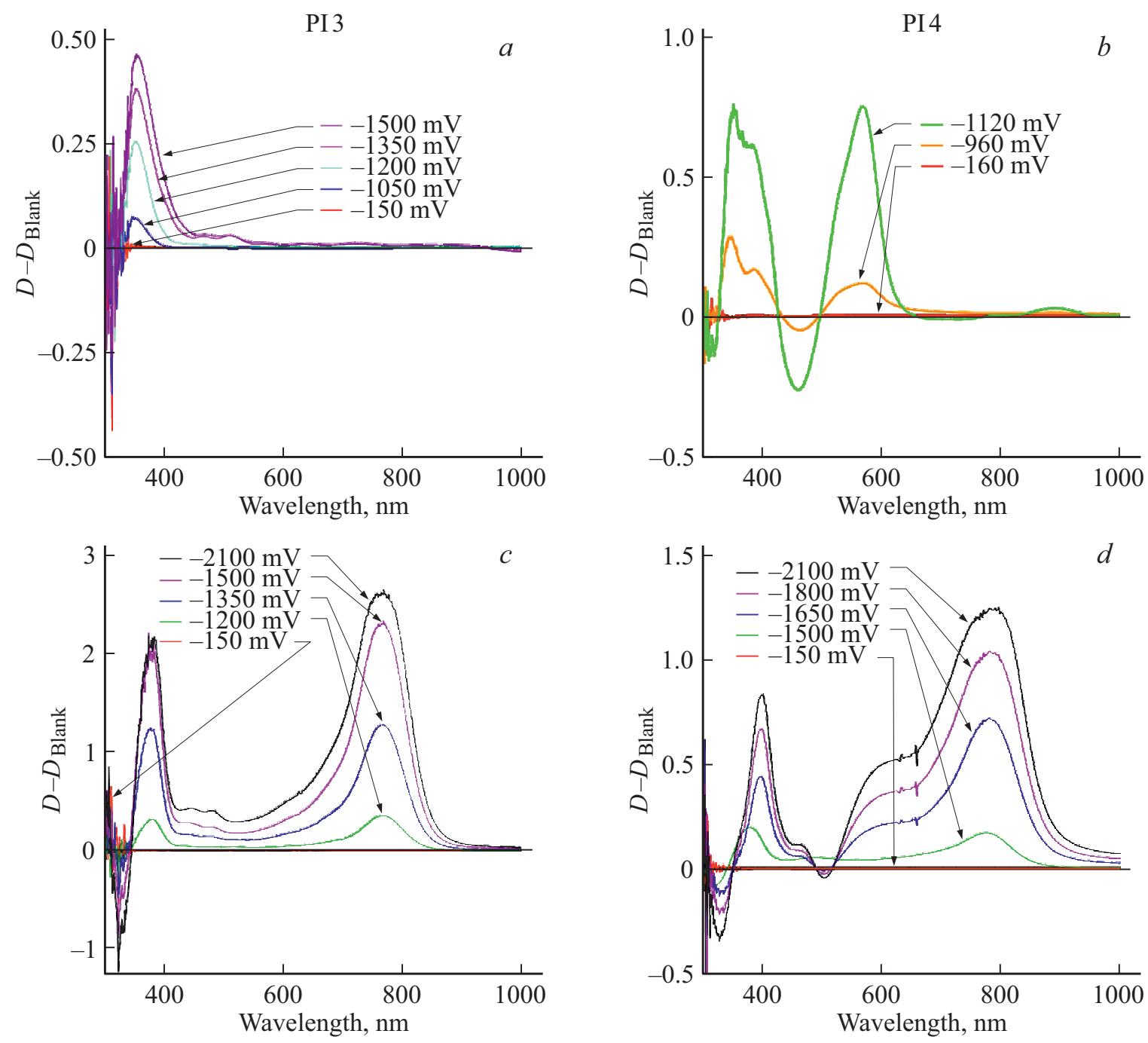

Рис. 5. Электрохромизм полиимидных пленок ПИ 3 (PI 3), ПИ 4 (PI 4) в восстановительной $(a, b)$ и окислительной $(c, d)$ областях потенциалов.

\section{Результаты и обсуждение}

Оптические свойства четырех образцов с пленками ПИ 1-4, нанесенными на кремниевые пластины, приведены в табл. 1. Данные таблицы показывают, что пленки на всех образцах имеют толщину в диапазоне $28-45 \mathrm{~nm}$ и довольно высокое для органических покрытий значение показателя преломления: $n=1.642-1.691$ $(E=1.96 \mathrm{eV})$. Спектральные зависимости показателя преломления $n$ и коэффициента поглощения $\alpha$, полученные при решении обратной задачи эллипсометрии, приведены на рис. $3, a, b$. Как видно из данных рис. $3, b$, все исследованные в работе пленки имеют сильное поглощение света в видимой области спектра, главным образом в коротковолновой части. Вид спектров $n(E)$, $\alpha(E)$ сильно зависит от типа пендантной группы (рис. 1 , табл. 1): так, появление и дальнейшее усиление поглощения происходит в различных частях спектров, в существенной степени влияя на величину $E_{g}$. Основные пики поглощения лежат в диапазоне $4.22-4.39 \mathrm{eV}$ с компонентами при $3.81-4.09 \mathrm{eV}$. Пленка ПИ 4, кроме того, имеет максимум поглощения в более длинноволновой области при $E \sim 2.66 \mathrm{eV}$.

ПИ 1-4 обладают ярко выраженным электрохромным поведением. В условиях электрохимического восстановления в оптических спектрах полиимидных пленок ПИ 1-4 появляются полосы поглощения в ближней ультрафиолетовой и видимой областях, интенсивность которых зависит от приложенного потенциала (рис. $4, a, b$, рис. $5, a, b)$. Появление полос в видимой области $(П И ~ 1,2,4)$ наблюдается в том случае, когда приложенный потенциал достигает потенциала восстановления пендантных групп $(-1.63,-1.03,-0.95 \mathrm{~V}$ соответственно для $9 H$-тиоксантен-9-она, его S-диоксида и антрахинона). Для ПИ 3 , не содержащего пендантной группы, заметного электрохромизма в видимой области спектра $(400-750 \mathrm{~nm})$ не наблюдается, за исключением полос очень слабой интенсивности (рис. $5, a$, табл. 2). 
Электрохромное поведение полиимидных пленок можно объяснить образованием достаточно долгоживущих отрицательно заряженных состояний пендантных групп (анион-радикальных состояний), что полностью соответствует первой стадии механизма электрохимического восстановления соответствующих предшественников, а именно обратимому одноэлектронному переносу [17]. Заметим также, что появление полос поглощения в ультрафиолетовой области для всех пленок ПИ 1-4, скорее всего, связано с образованием анионных состояний диимидного фрагмента полиимидной цепи (рис. 1), поскольку электрохимическое восстановление полиимидов без пендантных групп представляет собой двухэлектронный процесс [18].

Электрохромное поведение ПИ 1-4 в области положительных потенциалов - окислительный электрохромизм (рис. $4, c, d$, рис. $5, c, d$ ) имеет ту же тенденцию, что и электрохромное поведение ПИ 1-4 в области восстановительных потенциалов, и соответствует результатам, полученным ранее для полиимидов [12]. В условиях электрохимического окисления все полиимиды ПИ 1-4 демонстрируют интенсивные полосы поглощения в видимой и ближней ИК областях спектра, которые характеризуются заметным батохромным сдвигом по сравнению с поглощениями в восстановительной области потенциалов (рис. 4,5).

Из данных табл. 2 следует, что в условиях электрохимического восстановления полоса поглощения $\lambda_{1}$ с заметным батохромным сдвигом относительно соответствующей полосы $\lambda_{1}$ нейтральной пленки может быть отнесена к электронным переходам частиц, образующихся в результате одноэлектронного переноса на полимерную цепь, поскольку она наблюдается для всех ПИ, в том числе и ПИ 3 , не содержащего пендантной группы. Полосы $\lambda_{2}$, возможно, имеют смешанную природу, а полосы $\lambda_{3}$ (см. также рис. $4, a, b$, рис. $5, b$ ) относятся к оптическому поглощению одноэлектронновосстановленных пендантных групп, поскольку для ПИ 3 не наблюдается поглощений в этой области во всем изученном диапазоне потенциалов (рис. $5, a)$.

\section{Заключение}

Таким образом, в настоящей работе изучены оптические свойства тонких полиимидных пленок, полученных методом центрифугирования из растворов амбиполярных полиимидов, в том числе содержащих электрохимически активные пендантные группы на основе $9 \mathrm{H}$ тиоксантен-9-она, его S-диоксидного производного и антрахинона. Показано, что оптические свойства пленок, в частности ширина запрещенной зоны, зависят от природы пендантных групп. По данным эллипсометрии при введении пендантных групп тиоксантенонового ряда в структуру полиимида ширина запрещенной зоны возрастает в среднем на $0.93 \mathrm{eV}$ по сравнению с полиимидом без пендантной группы и полиимидом, содер- жащим антрахиноновую пендантную группу. Поскольку известно, что окно памяти мемристора увеличивается с увеличением ширины запрещенной зоны, амбиполярные полиимиды с пендантными группами тиоксантенонового ряда, имеющие более высокие значения $E_{g}$ из всего ряда изученных полиимидов, представляют интерес для создания мемристоров на их основе. Отметим, что модельное устройство резистивной памяти, изготовленное на основе ПИ 4 с антрахиноновой пендантной группой и реализованное на ITO-платформе, продемонстрировало WORM-поведение [12].

\section{Благодарности}

Авторы выражает благодарность Химическому исследовательскому центру коллективного пользования СО РАН за помощь в проведении спектральных измерений электрохромных свойств полимеров.

\section{Финансирование работы}

Работа выполнена при поддержке Министерства науки и высшего образования РФ в рамках госзадания № 02382021-0006.

\section{Конфликт интересов}

Авторы заявляют об отсутствии конфликта интересов.

\section{Список литературы}

[1] Gritsenko V.A., Islamov D.R. Physics of Dielectric Films: Charge Transport Mechanism and Physical Principles of Memory Devices. Novosibirsk: Parallel, 2017. 351 p.

[2] Nasyrov K.A., Gritsenko V.A. // Physics Uspekhi. 2013. V. 56. P. 999.

[3] Frenkel J. // Phys. Rev. 1938. V. 54. N 8. P. 647.

[4] Gismatulin A.A., Orlov O.M., Gritsenko V.A., Krasnikov G.Ya. Chaos, Solitons, and Fractals. 2021. V. 142. P. 110458.

[5] Lin W.-P., Liu S.-J., Gong T., Zhao Q., Huang W. // Adv. Mater. 2014. V. 26. P. 570.

[6] Ling Q.-D., Liaw D.-J., Zhu C., Chan D.S.-H., Kang E.-T., Neoh K.-G. // Prog. Polym. Sci. 2008. V. 33. P. 917.

[7] Kim Y., Cook S., Choulis S.A., Nelso J., Durrant J.R., Bradley D.D.C. // Chem. Mater. 2004. V. 16. P. 4812.

[8] Kim Y., Oh E., Choi D., Ha C.S. // Nanotechnology. 2004. V. 15. P. 149.

[9] Liu Y., Zhou Z., Qu L., Zou B., Chen Z., Zhang Y., Liu S., Chi Z., Chena X., Xu J. // Mater. Chem. Front. 2017. V. 1. P. 326.

[10] Heremans P., Gelinck G.H., Müller, Baeg K.J., Kim D.Y., Noh Y.Y. // Chem. Mater. 2011. V. 23. P. 341.

[11] You N.H., Chueh C.C., Liu C.L., Ueda M., Chen W.C. // Macromolecules. 2009. V. 42. P. 4456.

[12] Hu Y.-C., Chen C.-J., Yen H.-J., Lin K.-Y., Yeh J.-M., Chenac W.-C. Liou G.-S. // J. Mater. Chem. 2012. V. 22. P. 20394. 
[13] Odintsov D.S., Shundrina I.K., Os'kina I.A., Oleynik I.V., Beckmann J., Shundrin L.A. // Polym. Chem. 2020. V. 11. P. 2243.

[14] Рыхлицкий С.В., Спесивцев Е.В., Швеи, В.А., Прокопьев В.Ю. // Приборы и техника эксперимента. 2012. Т. 2. C. 161.

[15] Tompkins H., Irene E.A. Handbook of Ellipsometry. William Andrew Publishing, Springer, 2005.

[16] Грищенко В.А., Кручинин В.Н., Просвирин И.П., Новиков Ю.Н., Чин А., Володин В.А. // ЖЭТФ. 2019. Т. 159. Вып. 5(11). C. 1003. doi $10.1134 / \mathrm{S} 0044451019110166$

[17] Vasilieva N.V., Irtegova I.G., Loskutov V.A., Shundrin L.A. // Mendeleev Commun. 2013. V. 23. P. 334.

[18] Mazur S., Lugg P.S., Yarnitzky C. // J. Electrochem. Soc.: Electrochem. Sci. Technol. 1987. V. 134. N 2. P. 346. 